\title{
OPEN
}

\section{Author Correction: The association between physical activity and low back pain: a systematic review and meta-analysis of observational studies}

\section{Hosam Alzahrani, Martin Mackey, Emmanuel Stamatakis, Joshua Robert Zadro \& Debra Shirley}

Correction to: Scientific Reports https://doi.org/10.1038/s41598-019-44664-8, published online 03 June 2019

The original version of this Article omitted an affiliation for Hosam Alzahrani. The correct affiliations are listed below:

Discipline of Physiotherapy, Faculty of Health Sciences, The University of Sydney, Sydney, Australia.

Department of Physiotherapy, College of Applied Medical Sciences, Taif University, Taif, Saudi Arabia.

This has now been corrected in the HTML and PDF versions of the Article, and in the accompanying Supplementary Information file.

(c) (i) Open Access This article is licensed under a Creative Commons Attribution 4.0 International cc) License, which permits use, sharing, adaptation, distribution and reproduction in any medium or format, as long as you give appropriate credit to the original author(s) and the source, provide a link to the Creative Commons license, and indicate if changes were made. The images or other third party material in this article are included in the article's Creative Commons license, unless indicated otherwise in a credit line to the material. If material is not included in the article's Creative Commons license and your intended use is not permitted by statutory regulation or exceeds the permitted use, you will need to obtain permission directly from the copyright holder. To view a copy of this license, visit http://creativecommons.org/licenses/by/4.0/.

(c) The Author(s) 2020 